\title{
DIALOGISMO EM TEXTOS PARA CRIANÇAS: NÍCOLAS E A ORQUESTRA DA LUA CHEIA
}

\section{RESUMO}

Eliane Aparecida Galvão Ribeiro Ferreira

eliane@assis.unesp.br Universidade Estadual Paulista "Júlio Mesquita Filho", Assis, Brasil.

\section{Thiago Alves Valente}

\section{kantav2005@gmail.com}

Universidade Estadual do Norte do

Paraná, Cornélio Procópio, Brasil.

\begin{abstract}
Este artigo analisa as obras Nícolas, escrito por Agnès Laroche, ilustrado por Stéphanie Augusseau, e traduzido por Isabelle Gamin e Rosana de Mont'Alverne Neto, e A orquestra da lua cheia, escrita e ilustrada por Jens Rassmus, com tradução de Sofia Mariutti, a partir da ideia de dialogismo de Bakhtin (1995) e de leitor implícito de Wolfgang Iser (1996). As obras se destacam pela qualidade do texto verbal integrada aos textos imagéticos relevantes para o leitor infantil. A construção identitária e os conflitos familiares apresentam-se nas obras que não se entregam a discursos maniqueístas e previsíveis, antes convidam à imaginação e à superação dos problemas por meio do pensar e do agir em um mundo, muitas vezes, pouco sensível às necessidades da criança. Embora os temas sejam comuns em livros infantis, ambos os textos são marcados por uma escrita criativa e interessante para as crianças leitoras.
\end{abstract}

PALAVRAS-CHAVE: Literatura Infantil. Leitura. Dialogismo. 


\section{INTRODUÇÃO}

Nas décadas pós-1990, o mercado editorial brasileiro encontra-se entre o excesso de literatura de entretenimento e o desejo de produzir obras de "qualidade estética", nota-se, porém, uma mudança de mentalidade quanto à relação entre ensino e literatura. A produção literária infantil, por meio da autocrítica, da manutenção da autenticidade, da conscientização, da metalinguagem, da dialogia e da intertextualidade, busca adequar-se às peculiaridades próprias do tipo de leitor a quem se destina, e conscientizá-lo em relação às descobertas que lhe cabe fazer no mundo. $O$ imaginário, então, é visto como instrumento de conquista do conhecimento de si e do mundo em que se vive.

Neste artigo, aborda-se a temática da infância pelo tema da individuação, o qual será realizado com a análise dos protagonistas de duas obras literárias de 2013: Nícolas, escrito por Agnès Laroche, ilustrado por Stéphanie Augusseau, originalmente publicado em francês e traduzido por Isabelle Gamin e Rosana de Mont'Alverne Neto; e A orquestra da lua cheia, escrita e ilustrada por Jens Rassmus, originalmente publicado em alemão, com tradução de Sofia Mariutti. As obras de Laroche (2013) e de Rassmus (2013), embora publicadas em países diversos - França e Alemanha -, pertencem, originalmente, a um mesmo campo cultural: o da produção literária infantil. Dessa forma, as negociações e os consensos que surgem representados nesses textos dialogam tanto com a realidade circundante, quanto com a produção literária do seu tempo.

O conceito de dialogia é tomado dos estudos de Diana Barros (1999), pautando-se em Bakhtin (1995). Seu desdobramento, para efeito desta análise, pauta-se na ideia de leitor implícito conforme Wolfgang Iser (1996). Este leitor, embora seja uma projeção da estrutura de apelo do texto que supõe um receptor, representa um leitor empírico: a criança contemporânea. Quanto às obras em análise, em ambos os textos literários, a representação da infância efetiva-se pela relação estética de interação e colaboração que o texto verbal estabelece com o imagético.

\section{O SUJEITO DONO DE SEU DESTINO}

A orquestra da lua cheia aborda, de forma crítica e cômica, a temática da individuação. Para tanto, configura-se como uma história fantástica, com ilustrações coloridas que capturam o olhar do pequeno leitor. Sua protagonista mirim, criativa, divertida e crítica, Ana, demonstra alegria de viver e resiste à ordem de sua irritadiça mãe para que vá dormir, gerando identificação com o pequeno leitor. Nessa resistência, planta bananeira na sala e cai no teto. A partir desse feito, sem que seus pais percebam, dirige-se para seu quarto e pela janela é convidada a entrar em um barco, cujos exóticos integrantes - monstros diversos de diferentes cores e tamanhos -, também, de ponta cabeça, são músicos que partem para realizar um show na Lua. Durante esse espetáculo, todos se assustam com a aproximação de um dragão mal-humorado que pede silêncio. A única que decide questioná-lo é Ana. Assim ela descobre que ele aprecia música, contudo, vive solitário e triste porque se sente rejeitado. Com 
sua inclusão no grupo de músicos, o conflito é solucionado. Ana retorna para casa satisfeita pela aventura e sucesso na inclusão de um novo amigo.

Nícolas, por sua vez, aborda de forma sensível a temática da individuação. Para tanto, apresenta o pequeno protagonista Nícolas que, a princípio, lastima o fato de não ser forte e grande, imaginando que tudo seria diferente, se ao menos ele fosse um super-herói, no caso, o "Super Nico". A frase representativa desse desejo aparece após uma frustração, no discurso indireto livre, conotando que, embora o narrador seja observador, seu discurso representa os pensamentos do herói e a eles adere: "Ah! Se ao menos ele pudesse se transformar..." (Laroche, 2013 , p. 5, destaque nosso). Após tantas situações, em que se vê subjugado pelos mais fortes, por ser tímido, distraído e pequeno, decide parar de fantasiar e assumir suas potencialidades de menino. Assim, Nícolas, pelo viés da conscientização, muda suas atitudes, desenvolve estratégias e percebe que pode conferir ajuda a si mesmo, bem como viver melhor e em sintonia com sua infância. Como é o centro do relato, seu nome confere título ao livro.

Tanto a obra A orquestra da lua cheia (2013), pelas ilustrações coloridas, caricaturais, dotadas de textura que lhes confere volume, projetando-as para os olhos do leitor, quanto Nícolas (2013), pelas ilustrações sensíveis compostas por traços arredondados, são atraentes para o leitor em formação. Além disso, a temática da individuação em ambas, a brevidade e a representação dos protagonistas como crianças inteligentes e criativas que conseguem superar suas limitações e carências geram identificação com o leitor mirim.

Se uma das funções de uma ilustração é a de fundar uma memória afetiva na criança, em Nícolas (2013) a imagem é predominante em relação ao texto verbal, embora ambos se complementem. Pela representação de um herói que revoluciona sua realidade, a partir de suas próprias forças, sua narrativa confere, pelas performances do herói, coragem ao leitor mirim, e pelas representações imagéticas, a constituição de memória e a desautomatização do olhar.

O projeto gráfico de um livro ilustrado, bem como as funções de suas ilustrações, revela uma intenção de leitura a partir da junção entre texto e imagem em um único objeto, ou seja, projetam um leitor implícito (ISER, 1996), instaurando o modo de ler, a sequenciação de ações e a temporalidade - por isso, revelam uma percepção de infância e de criança. Para Luís Camargo (1998), a partir das proposições de Jakobson, a imagem pode apresentar as seguintes funções: 1) narrativa, orientada para o referente com a intenção de situar o representado e suas transformações ou ações; 2) expressiva, orientada para o emissor da mensagem quando capaz de manifestar seus sentimentos e emoções; 3) estética, põe em relevo a forma ou configuração visual com o objetivo de sensibilizar por meio das cores ou sobreposições delas em pinceladas com textura, manchas, alternâncias, abstrações, linhas etc.; 4) lúdica, em que a imagem apresenta-se sob a forma de um jogo, seja em relação ao emissor, referente, à forma da mensagem visual, seja ao destinatário; 5) metalinguística, orientada para o próprio código visual com remissão ao universo da arte.

N’A orquestra da lua cheia prepondera o fantástico. Seu espaço da aventura é a Lua, cuja atmosfera noturna presentifica-se pelas cores intensas e ilustrações carregadas de sombras. Seu dinamismo é assegurado pela representação das personagens em movimento; pela disposição das cenas ilustradas ora em folha dupla ora em simples na página da direita ou da esquerda; e também, pela sua 
posição, ora conforme o olhar do leitor, ora de ponta cabeça em relação a este, obrigando-o a virar o livro para prosseguir com a leitura. Como objeto do "brincar", o livro é cativante e pode desautomatizar o olhar infantil acostumado a ilustrações dispostas sempre na mesma página e direção. Sua profusão de cores, ao compor os fundos das páginas, bem como personagens e cenários, atrai o olhar da criança. O predomínio de tons mais escuros e de sombras, nos espaços da aventura, confere atmosfera noturna adequada às peripécias da Orquestra da Lua Cheia.

Como se pode notar, o par antitético que estrutura o enredo é o da ordem e o da subversão, mesmo que esta se realize somente no plano do imaginário. Uma vez no espaço aventuresco, Ana se descobre capaz de dialogar com um cômico e caricatural dragão de bobes, que se tornara mal-humorado, pois precisou fugir para a Lua ao sofrer rejeição na Terra. Justamente, a protagonista, que não consegue conversar com os pais em casa, pois estes estão mais preocupados em ver televisão, convence esse dragão a participar da orquestra e, assim, também, se divertir. Pela leitura, a criança eleva sua autoestima, pois se reconhece semelhante à heroína, dotada de competência para refletir, resolver problemas e até fornecer ajuda. O senso crítico se estabelece na relação assimétrica dos adultos com as crianças.

A capa, em tons de azul, preto e branco, confere cenário noturno para suas ilustrações de ponta cabeça, em relação ao título. Nesse plano imagético, notamse uma imensa Lua e pequenos barcos com passageiros que a esse satélite se dirigem. Essa capa intriga a criança e desperta sua curiosidade, reforçando o título de que na lua cheia acontecerá algo. Como no primeiro barco, há também uma menina, a criança se identifica com ela e sente-se motivada à leitura. Assim, pela temática; pela cativante protagonista mirim; pelo viés crítico do enredo; pela possibilidade de ampliar os horizontes de expectativas da criança e desautomatizar seus conceitos prévios acerca de ilustração; o livro mostra-se emancipatório.

Nícolas também apresenta um enredo divertido e envolvente. Seu cenário de aventura é predominantemente o da escola. Seu enredo, pautado pelo humor, cuja temática da individuação é cativante para o pequeno leitor também em formação de sua identidade. Sua inovação recai no emprego do hibridismo de gêneros textuais, no emprego de margens e/ou abandonos delas na ilustração, e na materialidade do livro. A começar pelo formato do volume e pela textura do papel, nota-se que foi planejado para promover a confluência das duas linguagens: verbal e imagética.

A capa, com o pequeno Nícolas olhando para cima e saindo de sua cabeça um balão que forma uma figura incompleta, gera identificação com a criança, instaura uma lacuna e, por isto a instiga, pois de forma metonímica e catafórica, apresenta a imagem de uma cena que só será entendida durante a leitura. No transcorrer da narrativa, nota-se que toda vez em que Nícolas se sente frustrado ou incapaz de realizar uma performance, ele projeta em sua imaginação um super-herói, o "Super Nico", seu alter ego, que satisfará suas angústias. O reconhecimento dessa projeção em outras cenas confere ao pequeno leitor a sensação de prazer, pois esta se apresenta como um payoff, uma recompensa, por tê-la analisado na primeira leitura, e de poder, já que, pelo contexto, seu entendimento dessa imagem não só se completa, como surge ressignificado. 
Logo na cena de abertura, nota-se que, no plano verbal, o tratamento literário e, no plano imagético, o estético, caminham juntos, pois aparece de forma hiperbólica um pequenino e corado Nícolas, cuja altura chega aos joelhos dos adultos, andando entre imensas pernas no caminho para a escola. Essa dedução advém do fato de que o herói mirim carrega uma mochila escolar nas costas (LAROCHE, 2013, p. 4). No plano verbal, nota-se o recurso à função poética da linguagem, no emprego da metonímia e da antítese: "Nicolas mistura-se à multidão que vai e vem. A todas essas pernas enormes que o empurram, a todas essas sobrancelhas franzidas, ele gostaria de gritar: 'Vocês não veem que estão pisando nos meus pés?"' (LAROCHE, 2013, p. 5, destaque nosso). Percebe-se a representação do adulto no meio urbano, como alienado, apressado, insensível à presença da criança, ocupando espaço demasiado pela sua dimensão, e estressado, convidando o narrador à adesão ao pequeno herói pelo viés da crítica social. Esse adulto alheio ao incômodo da sua presença desastrada opõe-se ao senso crítico do herói que se frustra pela impotência de não poder gritar aos que pisam em seus pés. Sua vingança realiza-se na proporção de suas forças e vivências, ele imagina um Super Nico que mostra uma língua enorme para todos os transeuntes. Justamente, esse sentimento diverte o leitor mirim e permite-lhe identificação, pois representa formas comportamentais típicas de uma criança descontente.

Suas folhas de guarda são marcadas na folha dupla por folhas de árvores, que voam livremente. Algumas são vermelhas, o que pode levar o leitor a construir a hipótese de que há um clima de outono. Assim, atuam também como catáfora e metonímia que instauram lacunas e pedem confirmação de hipótese. Esta ocorre durante a leitura, ao se detectar que as personagens vestem roupas de inverno e as árvores representadas em duas cenas possuem pouquíssimas folhas (LAROCHE, 2013, p. 30-32).

A folha de rosto apresenta Nícolas muito vermelho e constrangido, sentado em sua carteira. Essa cena tende a comover o leitor, pois nota-se como ele é pequenino, uma vez que seus pezinhos não alcançam o chão, e também o instiga a acompanhar o relato, a fim de descobrir a razão para a atitude do protagonista. Ela será reconhecida durante a leitura, como a cena em que o professor o constrange diante da turma, ao chamar sua atenção por ter esquecido novamente o caderno (LAROCHE, 2013, p. 12-13). Essa folha de rosto também atua como catáfora, projetando o olhar do leitor adiante em busca de entendimento. Além disso, instaura lacunas, por isso convoca hipóteses que só poderão ser testadas durante a leitura.

Em Nícolas a imagem é narrativa, pertence a um continuum que conduz o olhar para baixo e para cima, para a esquerda e à direita. Os traços das personagens em movimento conferem dinamismo ao relato. As ilustrações se alteram quanto à disposição, aparecendo ora em folha dupla, ora em uma única página, ora margeadas, ora sem margem alguma e ora em quadrinhos. Assim, elas desautomatizam o olhar do leitor mirim a respeito de ilustrações sempre dispostas na mesma localização da página e da mesma forma que, por se surpreender com a sua disposição, ampliam seus horizontes de expectativas.

Como se pode notar, a comunicação em Nícolas ocorre por meio da presença de vazios intencionais que geram expectativa e tensão. Para que o diálogo entre texto e leitor resulte em interpretação, faz-se necessário que este projete a expectativa e a memória uma sobre a outra. Assim, durante a leitura, promovem- 
se sínteses que constituirão correlatos que, por sua vez, impulsionarão expectativas (ISER, 1996). Por meio desse processo, o receptor atualiza e modifica o objeto, desenvolvendo novas expectativas e perspectivas. O prazer da leitura desse livro ilustrado advém justamente da possibilidade de revisão de hipóteses e de vivência da fantasia e do ludismo, enfim da ampliação do imaginário. A expectativa que se constrói é a confirmação das hipóteses construídas durante a leitura e do desfecho com a superação pelo protagonista Nícolas de suas carências e limitações.

Suas ilustrações caricaturais em branco e preto, pelos traços simples, evocam os desenhos infantis em grafite, assim como alguns fundos esfumados, gerando identificação com a criança. Essas ilustrações são marcadas pela hipérbole, pelo exagero nos traços de determinadas características das personagens, como a cabeça de Nícolas e de todas as personagens mirins, em geral muito arredondadas que, por serem maiores que o corpo, evocam a ideia de inocência e fragilidade. Em contraposição, a barriga e o nariz proeminentes do professor, bem como suas sobrancelhas arqueadas em desaprovação e sua postura - em pé, olhando para baixo ao se dirigir a Nícolas, com os braços dobrados em ângulo agudo na cintura e com as mãos fechadas -, indicam o adulto irritado. Por sua vez, a expressão facial contrariada do valentão da escola, indica sua agressividade. As representações sociais dos personagens vão revelando que adultos e crianças podem ser repressores.

Embora as ilustrações sejam em preto e branco, elas são atraentes pelo humor que instauram. Elas individualizam o protagonista como dotado de sentimentos e emoções, pois somente essa personagem e seu alter ego - Super Nico - aparecem em algumas cenas com as bochechas, as orelhas, a língua, os olhos ou a boca em vermelho. Vale destacar que a mesma cor marca cada letra inicial dos parágrafos, despertando o olhar do leitor para a estruturação textual, conotando que a história está marcada também no plano verbal pelas emoções. Além disso, como a cor vermelha coloca em relevo as expressões do rosto do protagonista, manifestando suas emoções e sentimentos, suas representações revelam a função expressiva, direcionada ao emissor que se identifica com a personagem e, justamente, por isto, pode sentir empatia.

A função estética avulta na folha dupla, pelo contraste entre páginas sangradas, sem margem, e páginas margeadas, emolduradas por vazios e, na parte de baixo, pelo texto verbal. Além disso, pelo esfumar de alguns fundos, põe-se em relevo a configuração visual do cenário, das personagens, enfim da atmosfera, sensibilizando o leitor por meio da cor vermelha, que confere destaque às bochechas do protagonista, mostrando-o ora como um garotinho saudável e corado; ora, pelo uso intensivo dessa cor que avança pelas orelhas, como envergonhado em determinadas situações. As sobreposições de imagens aparecem na projeção imaginária do herói de um Super Nícolas que, bem ampliado, realiza performances, as quais visam cessar várias formas de opressão ao protagonista e/ou satisfazer seus desejos reprimidos.

Assim, esse super-herói, marcado pela hipérbole, demonstra também o emprego da função lúdica, pois sua imagem imensa apresenta-se sob a forma de um jogo antitético em relação ao protagonista reprimido, aparentemente impotente. Um exemplo do desdobramento no plano verbal desses recursos estilísticos pode ser notado na cena em que, para chegar à escola, andando entre a multidão que o empurra e pisa em seus pés, Nicolas imagina que "se tornaria o 
Super Nico, ele seria supre grande, super forte, e ele mostraria uma língua enorme para toda essa gente apressada!" (LAROCHE, 2013, p. 6-7, destaque nosso). No plano imagético, aparece a representação imaginária de Nícolas imenso e rindo, com a boca escancarada, mostrando uma imensa língua vermelha para os transeuntes (LAROCHE, 2013, p. 6-7). Em outras cenas de opressão, em que o valentão da escola o oprime, o protagonista imagina que o Super Nico o derruba (LAROCHE, 2013, p. 10-11); o mesmo super-herói castiga o professor que repreende Nícolas na frente de seus colegas (LAROCHE, 2013, p. 14-15); ou grita para liberar a frustração reprimida do protagonista de ter perdido seu lanche em um encontrão com outro colega que vive correndo no recreio (LAROCHE, 2013, p. 18-19); ou galanteia a pequena Violeta, cativando-a com um buquê de flores (LAROCHE, 2013, p. 22-23). Vale destacar que os castigos impostos pelo Super Nico são cativantes para o leitor mirim, pois imaginados na medida de suas forças, assim, ao professor passa-se a tarefa de copiar "sem levantar o nariz" (LAROCHE, 2013, p. 14) em cem linhas: "Eu nunca mais vou aborrecer o Nícolas, prometo, eu juro!" (LAROCHE, 2013, p. 15, itálico da autora). $O$ destaque gráfico no plano verbal tem por objetivo assinalar que essa frase jamais fora escrita, trata-se somente de uma projeção imaginária do pequeno Nícolas.

As margens em folha dupla aparecem nas cenas em que o protagonista imagina e projeta o Super Nico. Desse modo, como fecham toda cena, elas conotam que pertencem a um cenário restrito; o que compõem o imaginário de Nícolas. A moldura na folha dupla aparece em primeiro plano, evocando um quadro e indicando que há limítrofes para o olhar. Ela polariza o espaço para dentro, instaurando, a princípio, a força centrípeta. Mas como na margem de baixo há texto verbal, a moldura faz com que a cena tenha dois momentos e espaços cênicos para o olhar: do lado de fora - universo livresco de descanso para o olhar e do plano verbal -, e do lado de dentro - universo imaginário de Nícolas. A cena do plano conjunto assume, então, a perspectiva de um segundo plano em relação à moldura. Assim, a folha dupla explora, na imagem, a função metalinguística, pois a ilustradora solicita do leitor uma reflexão acerca da representação do imaginário em um livro. Indica, também, que as cenas de imaginação de Nícolas, embora integrem o plano conjunto, pertencem também a outros espaços: o do livro, no caso, à capa, e o da realidade, em que também há meninos imaginativos. As cenas cotidianas aparecem em imagens sangradas, como que em continuação com o universo já conhecido pelo leitor. A ausência nessas cenas de moldura convoca o olhar crítico da criança a se estender indefinidamente no universo, de forma centrífuga, conotando que o representado é a continuidade do mundo empírico.

Como a obra é marcada pelo hibridismo resultante da mescla de gêneros textuais, ela dialoga com os quadrinhos: ao apresentar a noite mal dormida do herói em posições diversas na cama, lutando contra a insônia e suas angústias. Nota-se na folha dupla (LAROCHE, 2013, p. 24-25), a sequencialidade de ações que remetem a um travelling, o qual pode ser acompanhado com prazer gradativo pelo leitor, na mesma proporção do aumento da tensão do herói.

$\mathrm{Na}$ folha dupla seguinte (LAROCHE, 2013, p. 26-27), há duas cenas emolduradas, indicando que a luta de Nícolas com seus desejos de ser um superherói se prolonga, mas, por determinação dele, ela finda. Esse findar está representado na implosão do Super Nico imaginário (LAROCHE, 2013, p. 27). A 
seguir, em cena também na folha dupla, mas sangrada, vê-se o herói sorrindo diante do espelho, pois descobre a si mesmo, assume sua identidade e sua responsabilidade na condução de seus atos: "Eu me chamo Nícolas. Eu não sou grande, eu não sou forte, e, amanhã, eu vou oferecer um buquê de margaridas para Violeta!" (LAROCHE, 2013, p. 29). No plano verbal, nota-se pela primeira vez a assunção da primeira pessoa do discurso: "eu", mostrando que o herói deixa de fantasiar, de omitir seus desejos e sonhos, e passa a dominar e expressar seu próprio discurso. Essa folha dupla dialoga com o teatro, pois ao criar em seu fundo um contorno esfumaçado - um semicírculo - ao redor de Nícolas diante do espelho, evoca a ideia de holofote, de iluminação que se projeta sobre o herói. Desse modo, o plano do significante e o do significado expressam a mesma mensagem libertária: a do empoderamento do protagonista que assume o centro e o rumo de sua existência.

As cenas seguintes, também, dialogam com os quadrinhos, pois mostram Nícolas realizando ações pontuais como: organizar, antes de sair de casa, todo seu material escolar na mochila; eleger outro caminho para a escola, o qual passa por um bosque distante das pernas dos adultos; colher flores para Violeta (LAROCHE, 2013, p. 30); comer seu lanche no banco com as pernas trançadas por debaixo, para não cair com um esbarrão dos colegas (LAROCHE, 2013, p. 31); enfrentar a tirania do fortão, afirmando que comunicará a opressão ao professor e, talvez, até ao pai do menino (LAROCHE, 2013, p. 32); finalmente, entregar um ramalhete de dentes de leão para Violeta (LAROCHE, 2013, p. 33).

A última cena, em folha dupla, mostra o congraçamento e, justamente por isto, ela está manchada de vermelho. Esta cor emoldura predominantemente Nícolas e um pouco Violeta. A predominância da cor põe em destaque as emoções, no caso de Nícolas, a felicidade e a satisfação pelo beijo recebido de Violeta (LAROCHE, 2013, p. 34-35). No caso da heroína, o agradecimento pelas flores e a percepção de que é considerada por Nícolas.

\section{CONCLUSÃO}

Em síntese, as obras apresentam qualidade estética em seu tratamento do tema da individuação e na relação de interação e colaboração entre plano verbal e imagético. Sua abordagem da alienação dos adultos que, em meio urbano, desrespeitam seus limites, ignorando a criança; da falta de adequação do herói em seu ambiente escolar e/ou da reprovação de suas atitudes, diz respeito a um contexto contemporâneo.

O tratamento da temática da individuação, pelo viés da valoração das potencialidades da criança, apresentadas como autônomas e superiores aos adultos que as cercam no convívio social, eleva a autoestima do leitor mirim e confere-Ihe coragem para as próprias lutas, em especial, as que exigem mudança interna, emocional, individual, a fim de lidar com o contexto externo. Para Ana Margarida Ramos (2015, p. 152), na literatura infantil contemporânea, "a urbanidade e a agitação das sociedades contemporâneas, reguladas por ritmos ferozes e avassaladores, podem implicar uma valorização alternativa de um certo intimismo e introspeção que perpassa muitas das edições atuais." 
Justamente, esse intimismo, configurado em reavaliação de si mesmo com planejamento de novas ações, leva ambos personagens à superação de suas carências de ordem diversas. Por projeção neles, o leitor mirim empodera-se, por sua vez, em um processo de superação pelo viés lúdico, contudo, existencial. 


\title{
DIALOGISM IN CHILDREN'S TEXTS: NÍCOLAS AND A ORQUESTRA DA LUA CHEIA
}

\begin{abstract}
This article analyzes the literary book Nícolas, written by Agnès Laroche, illustrated by Stéphanie Augusseau, and translated by Isabelle Gamin and Rosana Mont'Alverne Neto, and $A$ orquestra da lua cheia, written and illustrated by Jens Rassmus, translated by Sofia Mariutti. In order to do so, we use the idea of dialogism by Bakhtin (1995) and Wolfgang Iser (1990)'s concept of the implied reader. The books are important because their quality is composed of verbal texts integrated with relevant illustrations for the child reader. The construction of the identity and family conflicts are presented in stories that don't bring manichean and predictable speeches. Instead of that, they invite the reader to imagine and to solve the problems through thinking and action in a world not often very sensitive to the child's needs. Although the themes are common in children books, both texts are marked by creative and interesting writing to the child reader.
\end{abstract}

KEYWORDS: Children's Literature. Reading. Dialogism. 


\section{REFERÊNCIAS}

BAKHTIN, Mikhail. Marxismo e filosofia da linguagem: problemas fundamentais do Método Sociológico na Ciência da Linguagem. Trad. Michel Lahud; Yara F. Vieira. 7.ed. São Paulo: Hucitec, 1995.

BARROS, Diana P. de. "Dialogismo, polifonia e enunciação". In: FIORIN,José L. (Orgs.). Dialogismo, polifonia, intertextualidade: em torno de Bakthin. SãoPaulo: Editora da Universidade de São Paulo, 1999, p. 1-9.

CAMARgO, Luís H. de. Poesia infantil e ilustração: estudo sobre $\mathrm{Ou}$ isto ou aquilo, de Cecília Meireles. 214 p. Dissertação de Mestrado pela Universidade estadual de Campinas - UNICAMP, São Paulo, 1998.

ISER, Wolfgang. $\mathbf{O}$ ato da leitura: uma teoria do efeito estético. Trad. Johannes Kretschmer. São Paulo: Ed. 34, 1996. vol. 1.

LAROCHE, Agnès. Nícolas. Ilustr. Stéphanie Augusseau. Trad. Isabelle Gamin e Rosana de Mont'Alverne Neto. Belo Horizonte: Aletria, 2013.

RAMOS, Ana Margarida. Reescrever a morte na narrativa infantil portuguesa contemporânea. Tropelías: Revista de Teoría de la Literatura y Literatura Comparada, 23,p. 151-162, 2015.

RASSMUS, Jens. A orquestra da lua cheia. Trad. Sofia Mariutti. São Paulo: Reviravolta, 2013. 
Recebido: 06 fev. 2017

Aprovado: 13 mai. 2017

DOI: 10.3895/rl.v19n24.5410

Como citar: VALENTE, Thiago Alves; FERREIRA, Eliane Aparecida Galvão Ribeiro. Dialogismos em textos para crianças: Nícolas e a orquestra da lua cheia. R. Letras, Curitiba, v. 19, n. 24, p. 32-42, mar 2017. Disponível em: <https://periodicos.utfpr.edu.br/rl>. Acesso em: XXX

Direito autoral: Este artigo está licenciado sob os termos da Licença Creative Commons-Atribuição 4.0 Internacional.

(c) (i) 